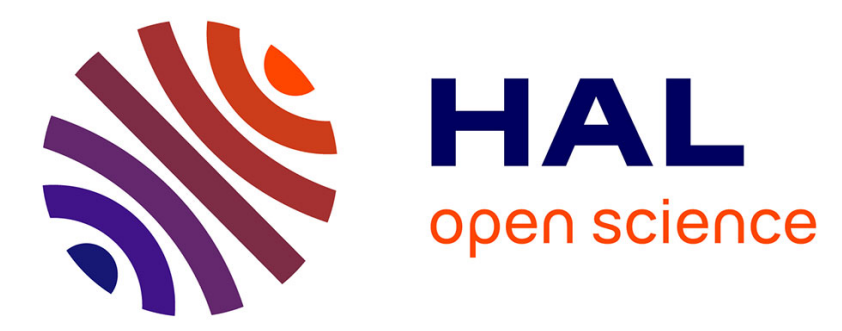

\title{
Geographic variation in North American gypsy moth cycles: subharmonics, generalist predators, and spatial coupling
}

Ottar Bjørnstad, Christelle Robinet, Andrew Liebhold

\section{- To cite this version:}

Ottar Bjørnstad, Christelle Robinet, Andrew Liebhold. Geographic variation in North American gypsy moth cycles: subharmonics, generalist predators, and spatial coupling. Ecology, 2010, 9 (1), pp.106-118. 10.1890/08-1246.1 . hal-02663129

\section{HAL Id: hal-02663129 \\ https://hal.inrae.fr/hal-02663129}

Submitted on 31 May 2020

HAL is a multi-disciplinary open access archive for the deposit and dissemination of scientific research documents, whether they are published or not. The documents may come from teaching and research institutions in France or abroad, or from public or private research centers.
L'archive ouverte pluridisciplinaire HAL, est destinée au dépôt et à la diffusion de documents scientifiques de niveau recherche, publiés ou non, émanant des établissements d'enseignement et de recherche français ou étrangers, des laboratoires publics ou privés. 
Version définitive du manuscrit publié dans / Final version of the manuscript published in : Ecology. 2010, 9(1), 106-118

Geographic variation in the North-American gypsy moth population cycles: subharmonics, generalist predators and spatial coupling

Ottar N. Bjørnstad ${ }^{1, *}$, Christelle Robinet ${ }^{2,3, * *}$ and Andrew M. Liebhold ${ }^{3, * * *}$

${ }^{1}$ Departments of Entomology and Biology, 501 ASI Bldg, Penn State University, University Park, Pennsylvania 16802, USA

${ }^{2}$ INRA, UR 633 Zoologie Forestière, F-45075 Orléans, France

${ }^{3}$ Northern Research Station, USDA Forest Service, 180 Canfield St., Morgantown, West Virginia 26505, USA

* onb1@psu.edu ; Tel.: +1.814.863.2983; Fax: +1.814.865.3048

** robinet@orleans.inra.fr ; Tel.: +33.2.38.41.78.00; Fax: +33.2.38.41.78.79

*** aliebhold@fs.fed.us ; Tel.: +1.304.285.1512; Fax: +1.304.285.1505

Short title for page heading: Subharmonics in the gypsy moth cycle 


\section{ABSTRACT}

Many defoliating forest lepidopterans cause predictable periodic deforestation. Several of these species exhibit geographical variation in both the strength of periodic behavior and the frequency of cycles. The mathematical models used to describe the population dynamics of such species commonly predicts that gradual variation in the underlying ecological mechanisms may lead to punctuated (sub-harmonic) variation in outbreak cycles through period-doubling cascades. Yet there are relatively few examples of such behavior in nature. Gypsy moth, Lymantria dispar, appears to provide an interesting example of this phenomenon; prior evidence suggested that outbreaks are twice as frequent in xeric low-productivity forests than in more productive mesic forests. In this study we first introduce a statistical method for estimating outbreak periodicity from space-time defoliation data that are collected with spatial error. We use this method to confirm the existence of variation in cyclicity among different forest types: Some forest types exhibit a statistical 4-5 year period in outbreak dynamics, some a 9-10 year, and some a dominant 9-10 year period with a subdominant superharmonic. We then use a theoretical model involving gypsy moth, pathogens and predators to investigate the possible role of geographical variation in generalist predator populations as the cause of this variation in dynamics. Generalist predators are known to influence the dynamics of many forest Lepidoptera and variation in the habitat that affects predator abundance could influence the dynamics of their lepidopteran prey. The model predicts that the period of gypsy moth oscillations should be positively associated with predator carrying capacity and that variation in the carrying capacity provides a parsimonious explanation of previous reports of geographical variation in gypsy moth periodicity. Furthermore, a simple 2-patch spatial extension of the model shows that in the presence of spatial coupling, superharmonic attractors can coexist whereas nonharmonic attractors (i.e. where the cycle lengths are not integer multiples of one another) cannot. 
Keywords: Nonparametric spatial covariance function, spatiotemporal dynamics, virus-insect interactions, Allee effect, Lymantria dispar.

\section{INTRODUCTION}

The dramatic fluctuations of certain foliage-feeding forest insects have long attracted the attention of ecologists (Varley et al. 1973). Though most forest insects remain at innocuous levels, a few populations episodically reach extreme densities over large areas, causing massive defoliation of their host trees. One characteristic of these outbreaks that has attracted particular attention is the periodic nature of the oscillations (Baltensweiler et al. 1977, Myers 1988, Kendall et al. 1998, Liebhold and Kamata 2000, Esper et al. 2007). While both the regularity and period of oscillations varies from species to species, there is also ample evidence of geographic variation in dynamics among populations of any given species. In Fennoscandia, for example, northern populations of the autumnal moth, Epirrita autumnata, display periodic oscillations that cause widespread defoliation of host trees while more southerly populations show little evidence of periodicity (Ruohomaki et al. 1997, Klemola et al. 2002). Populations of the jack pine budworm, Choristoneura pinus, located in dry sites exhibit oscillations with a period of 5-6 years but populations in mesic sites are characterized by outbreak periods of ca. 10 years (Volney and McCullough 1994). Finally, populations of the gypsy moth, Lymantria dispar (L.), oscillate with a dominant period of 9-11 years in most locations, yet some forest types see more frequent outbreaks (Miller et al. 1989, Williams and Liebhold 1995, Johnson et al. 2005, Johnson et al. 2006a). These two latter cases may represent intriguing examples of how gradual variation in underlying ecological mechanisms may lead to punctuated (sub-harmonic) changes in cycle periods: a phenomenon frequently predicted by mathematical models but relatively rarely seen in field populations.

Though geographical variation in natural enemy communities has been advanced as a cause of geographic variation in dynamics in certain cyclic species including rodents (e.g. Hansson and Henttonen 1985, Bjørnstad et al. 1995) and moths (Klemola et al. 2002), the theoretical plausibility 
of this explanation remains unresolved for most systems (but see Turchin and Hanski 1997 for a rare example involving Scandinavian rodents). In this study, we use gypsy moth, Lymantria dispar, outbreaks in North America as a model system for studying the cause of geographical variation in forest insect population cycles. This species periodically causes extensive defoliation over thousands of hectares of temperate forests. In a previous analysis of extensive spatiotemporal data from North America, Johnson et al. (2006a) showed that gypsy moth oscillations in several xeric forest types appeared to be on 4-5 year cycles whereas populations in mesic forest types exhibited a dominant 9-10 year period. Spectra also indicated the presence of a subdominant 4-5 year superharmonics in some of the intermediate forest types. In order to confirm this variation in periodicity and the existence of superharmonic oscillatory behavior, we develop a new statistical method for estimating outbreak periodicity from space-time defoliation data collected with spatial error - spurious super-harmonics can potentially arise when data are aggregated across landscapes from two harmonic outbreak cycles coexisting in anti-phase of one another. We use this method to confirm that the existence of the superharmonic oscillations is not a statistical artifact of aggregating data from such spatially anti-synchronous populations. We then analyze a non-spatial and a two-patch model for gypsy moth population dynamics to elucidate the community ecological origins of the geographic variation and spatial mechanisms that may account for the coexisting subharmonics.

The greater frequency of gypsy moth outbreaks in dry vs. moist North American oak forests is an observation that has been made over many years of research (Bess et al. 1947, Houston and Valentine 1977). Varying pressure by generalist predators among forest stands has been proposed as a plausible explanation for the differences (Smith 1985, Liebhold et al. 2005). In current theoretical parlance, the putative mechanism would be that where generalist predators are abundant, they have the capability to induce a weak Allee effect in gypsy moth populations. That is, population growth rates are greatly depressed by predation at low densities so as to slow population growth during periods of increase, but not enough to induce population collapse (which would represent a strong 
Allee effect; Wang and Kot 2001). While small mammal predation on gypsy moth pupae has been shown to play an important role in gypsy moth demographics (Bess et al. 1947, Elkinton et al. 1996, Jones et al. 1998, Liebhold et al. 2000, Dwyer et al. 2004), it is unclear how this influences the periodicity of gypsy moth outbreaks. We use a mathematical model to quantify this relationship. In particular, we investigate (i) whether the transition from 5 to 10 year cycles can be explained by variation in generalist predator densities and (ii) whether the superharmonics seen in the data can be explained by the interactions with such natural enemies. We use a model derived from Dwyer et al. (2004) to demonstrate that while the intrinsic outbreak dynamics are caused by specialist pathogenhost interactions, the dominant period of oscillations is directly related to the generalist predator carrying capacity, thereby explaining the previously hypothesized association. Furthermore, we show that at high predator levels a weak Allee effect is induced and subdominant 5-6-year superharmonics emerge in the model. Moreover, a two-patch version of our model shows that in the presence of spatial coupling, super-harmonic attractors can coexist whereas non-harmonic attractors (i.e. where the cycle lengths are not integer multiples of one another) cannot.

\section{METHODS AND MODELS}

\section{Estimating outbreak periodicity from space-time data with spatial error}

State governments have been monitoring defoliating outbreaks of gypsy moth via aerial surveys since the early 1960's or before, and systematic archiving of historical maps began in 1975. During annual aerial surveys, observers sketch the extent of defoliation from the air on paper or digital maps (Ciesla 2000) which are then compiled as a series of polygons in a geographical information system (GIS) (Liebhold et al. 1997). Our analyses were conducted using 2 x 2 km grids of 0/1 data indicating the presence of defoliation in each grid cell derived from the 1975-2002 annual GIS layers. Visible defoliation is a useful but imperfect proxy for abundance (Bjørnstad et al. 2002). Moreover, aerial surveillance is inherently associated with some level of spatial error (Ciesla 2000). Finally, the underlying spatiotemporal dynamics of these pests are somewhat 
spatially stochastic (due to micro-geographical variation in environmental conditions), so important spatio-temporal patterns may only be borne out across broader spatial domains.

The autocorrelation function and the associated periodogram (e.g. Priestley 1981) are the most commonly used statistical methods for estimating cycle periods in outbreak data (Kendall et al. 1998, Berryman 2002). Previously, we applied these methods to meso-scale and forest-type aggregated time series of gypsy moth defoliation (Johnson et al. 2006a). The conclusion was that outbreaks in mesic forest type groups such as oak-hickory and maple-beech-birch tend to recur every 9-10 years whereas outbreaks in more xeric forest types return every 4-5 years. These results are consistent with the previous scientific literature (Bess et al. 1947, Houston and Valentine 1977) that reports more frequent gypsy moth outbreaks in dry oak-dominated stands. Conclusions regarding 'super-harmonic' cycles (i.e. cycles with, for example, a half-period duration) based on analyses of spatially aggregated data, may however be spurious if the spatial aggregation encompasses areas of uncorrelated outbreak cycles (see for example Grenfell et al. 2001, Ferrari et al. 2008).

The 'safe' way to avoid spurious harmonics is to analyze the defoliation time series at their finest available resolution. We have attempted this, but our efforts were thwarted by spatial errors and/or the inherent local stochasticities (Bjornstad and Liebhold, unpublished results), because while at the meso-scale outbreaks tended to follow the broad harmonic scheme, the outbreak records for any given grid cell could be “hit-or-miss”. Here we take a ‘spatial-smoothing' approach to resolving this, building on the time-lagged spatial correlation approach developed in Bjørnstad et al. (2002) and Seabloom et al. (2005). Consider the panel of spatially-indexed time series $\mathrm{z}_{\mathrm{i}, \mathrm{t}}$ where $i$ represents spatial location and $t$ represents time. In the absence of spatial error the lag- $l$ autocorrelation at location $i$ is as according to standard time series theory (e.g. Priestley 1981):

$$
\sum_{t=0}^{T-l}\left(Z_{i, t}-\overline{Z_{i}}\right)\left(z_{i, t-l}-\overline{Z_{i}}\right) / \sigma_{i}^{2},
$$


where $\overline{z_{i}}$ represents the mean of the time series, $\sigma_{i}$ represents the standard deviations. Spatial errors, however, will bias our estimates towards zero. We therefore consider the more general family of lag- $l$ spatial correlation between the observation in year $t$ at location $i$ and year $t+l$ at location $j$ as a function of their spatial distance $\delta_{\mathrm{ij}}$. The time-lagged nonparametric spatial crosscorrelation function can than be estimated as

$$
\tilde{C}(\delta, l)=\frac{\sum_{i=1}^{n} \sum_{j=1}^{n} K\left(\delta_{i j}\right) w_{i j, l}}{\sum_{i=1}^{n} \sum_{j=1}^{n} K\left(\delta_{i j}\right)},
$$

where $K()$ is an equivalent kernel smoother (we use a smoothing spline, according to previously published methods: Bjørnstad and Falck 2001). The cross-correlation, $w_{i j, l}$, between two time series of abundance, $\underline{z_{i}}$, at location $i$ and, $z_{j}$, at location $j$ (either at similar or different locations) lagged by $l$ years relative to each other (either in the same year, $l=0$, or in lagged years) is given by $w_{i j, l}=\left(\underline{z_{i}}-\overline{z_{i}}\right) \times\left(\underline{z_{j, l}}-\overline{z_{j}}\right)^{T} / \sigma_{i} \sigma_{j}$, underscored symbols represents vectors (time series), $\times$ denotes matrix multiplication, and ${ }^{\mathrm{T}}$ denotes matrix-transposition. The estimated time-lagged crosscorrelation will depend both on spatial distance and temporal lag (Figure 1).

The sequence of time-lagged 'y-intercepts', $\tilde{C}(0, l)$, represents our 'spatial-smoothing' estimate of the temporal autocorrelation function (visualized, for example, in figure 1a and b). Our spatial-smoothing estimator will be biased towards zero for two distinct reasons. Firstly, the spatial error will translate into significant observational errors; Observational errors on any times-series will bias its estimated autocorrelation function towards zero. Secondly, our outbreak data approximates the true underlying gypsy moth abundance using a binary switch. Epperson (1995) discusses the consequence of studying such binary data in the context of spatial population genetics and show that the overall shape of the underlying spatial correlogram is preserved but all estimated correlations are strongly biased towards zero (see also simulations in Bjørnstad and Falck 2001). In the face of the combined effects of both of these sources of error, we use the bootstrap to ascertain statistical significance of our spatial-smoothing estimator. To erect bootstrap confidence intervals 
we resample time-series among locations with replacement (Bjørnstad and Falck 2001). For each forest type, we used 500 bootstrap replicates for each ' $y$-intercept'-estimator of the ACF in the sequence of time-lagged nonparametric spatial covariance functions (Bjørnstad et al. 2002, Seabloom et al. 2005). We considered time lags out to 12 years (covering the dominant periodicities reported for the gypsy moth (Johnson et al. 2005).

\section{A natural enemy model}

We propose an initially non-spatial but subsequently two-patch model to explore the transition in dynamics and distinct super-harmonics observed in this system.

The gypsy moth is a univoltine species that over-winters in the egg stage. Larvae hatch in the spring and emerge as short-lived adults following a brief pupal period. Females lay 50-1000 eggs in a single conspicuous egg-mass. Two distinct groups of natural enemies are thought to induce critical density-dependent mortality during the life cycle: epizootics of specialist pathogens (both virual and fungal) kill larvae, particularly at high densities (Doane 1970, Campbell 1975, Dwyer and Elkinton 1993); and generalist predators (particularly small mammals) eat pupae (Campbell and Sloan 1977, Smith 1985, Elkinton et al. 1996, Jones et al. 1998). Other natural enemies, such as specialist and generalist parasitoids, also attack the gypsy moth. However, Dwyer et al. (2004) showed that a model that incorporated pathogens and predators could account for the key features of the population cycles observed in field gypsy moth populations. To dissect the effects of generalist predators on gypsy moth oscillations, we build on the model developed by Dwyer et al. (2004). For our purpose we modify the model in three main ways: (i) the natural enemies are assumed to operate in a sequential fashion to better reflect how the virus affects larvae and the predators affect pupae, (ii) we include an explicit model for the predator population, and (iii) we assume a Type II functional response for the predator.

The logic of the model is as follows: Each female is on average assumed to produce $\lambda$ offspring. Of these, a density-dependent fraction of the larvae, $I\left(N_{t}, Z_{t}\right)$, will succumb to disease, 
where $N_{t}$ and $Z_{t}$ represents the number of uninfected and infected individuals respectively. As derived by Dwyer et al. (2000, 2004), this fraction can be calculated according to the implicit equation for the expected final epidemic size:

$$
I\left(N_{t}, Z_{t}\right)=1-\left(1+\frac{\bar{v}}{\mu k}\left(N_{t} I\left(N_{t}, Z_{t}\right)+\rho Z_{t}\right)\right)^{-k},
$$

where $\mu$ is the rate at which cadavers lose infectiousness, $\rho$ is the susceptibility of hatchlings relative to later-stage larvae, $\bar{v}$ is the average transmission rate, and $k$ is the inverse squared coefficient of variation of transmission rate. The assumptions here are that the epizootic is rapid relative to the annual life-cycle of the host so that the epidemic will run it course during the duration of the larval period, and that there is Gamma distributed heterogeneity in susceptibility among hosts (Dwyer et al. 2000). The number of infectious larval cadavers in year $t+1$ is then

$$
Z_{t+1}=f \lambda N_{t} I\left(N_{t}, Z_{t}\right)
$$

where $f$ is the pathogen over-winter survival, and the number of hosts that survive to the pupal stage is:

$$
\tilde{N}_{t}=\lambda N_{t}\left(1-I\left(N_{t}, Z_{t}\right)\right)
$$

Predation by generalist rodent predators, such as deer mice (Peromyscus spp.), on pupae can be a large source of mortality particularly in low-density populations (Campbell and Sloan 1977, Smith 1985). However, these predator populations are generally not, in turn, affected by gypsy moth densities. They tend instead to depend on other food resources such as acorns, berries and other invertebrates (Elkinton et al. 1996, Jones et al. 1998). The fluctuations in predator populations 
can induce considerable variation among years and among sites in rates of predation (Yahner and Smith 1991, Elkinton et al. 1996, Jones et al. 1998, Liebhold et al. 2000, Goodwin et al. 2005). Here, we model temporal variation in predator populations according to a, possibly stochastic, Ricker model (though other models may be equally plausible):

$$
P_{t+1}=\exp \left(r_{t}\right) P_{t} \exp \left(1-\frac{P_{t}}{K}\right),
$$

where the instantaneous rate of increase, $r_{t}$, represents a constant or a sequence of independent identically distributed normal random deviates (with st.dev. $\tilde{\sigma}=0.3$ ), and $K$ represents the predator carrying capacity. Because dynamical consequences of predation is the focus of this study we have chosen to include stochasticity in this component of the model only, though other parts of the system is obviously also likely to be affected by temporal variability (Dwyer et al. 2004). Note that even though Peromyscus spp. have multiple generations per year, we think of $P$ as representing their abundance at the time that gypsy moth pupae are present in the field (usually in late June early July).

We assume a type II functional response of these predators (Elkinton et al. 2004, Schauber et al. 2004). The instantaneous rate of predation in any given year is then $P_{t} a c /\left(c+\tilde{N}_{t}\right)$, and the per capita probability of not succumbing to predation (in the absence of aggregation, interference, etc: Murdoch et al. 2003) is $\exp \left(-P_{t} a c \Delta t /\left(c+\tilde{N}_{t}\right)\right)$, where $\Delta t$ is the duration of the pupal stage (ca 10 days), and $a$ and $c$ are constants determining the maximum attack rate and the half-saturation point of the predators. By writing $c=b(2+\sqrt{3})$, the maximum predation rate of our type II model $(=1$ $\exp (-a P / 2))$ and the half saturation occur for the same host density $(\tilde{N}=(2+\sqrt{3}) b)$ as in Dwyer et al.'s (2004) type III model (see Supplementary material). For high predator abundance $(P=10)$, a value of $a=0.98$ gives a predation probability comparable to the empirical observations of Elkinton et al. (2004) of maximum daily predation probability of 0.4 . 
Our full model for the adult gypsy moth dynamics is then:

$$
N_{t+1}=\tilde{N}_{t} \exp \left(-\frac{a b(2+\sqrt{3}) P_{t}}{2\left(\tilde{N}_{t}+b(2+\sqrt{3})\right)}\right),
$$

where $\tilde{N}_{t}$ is as given by equation (5).

Predation on low density populations that operates via a Type II functional response is capable of introducing weak or strong Allee effects in prey populations (Courchamp et al. 1999, Gascoigne and Lipcius 2004). Because Allee effects can have profound influences on dynamics and are thought to be important in Gypsy moth dynamics (Johnson et al. 2006b, Tobin et al. 2007) we quantified Allee effects arising from this interaction between gypsy moths and predators using the realized per capita growth rate $R_{t}=N_{t+1} / N_{t}$. To study synergism or interference with the pathogen, we quantify emergent Allee effects in the absence of disease $\left(\tilde{N}_{t}=\lambda N_{t}\right)$ and in the presence of large epizootics (90\% prevalence; $\left.\tilde{N}_{t}=0.10 \lambda N_{t}\right)$.

We then examine the effects of predator carrying capacity on the periodicity of gypsy moth outbreaks. We only consider stochasticity in predator dynamics and present results based on 500 replicate simulations for each value of $K$, ranging from 0.1 to 9 by 0.1 (simulated over 200 years, using the last 100 iterations to quantify periodicity). We use periodograms to identify the strongest oscillatory periods of each simulated gypsy moth time series. For each predator carrying capacity, we calculate the average standardized spectra over the 500 simulations. We also investigate the purely deterministic model in which predator abundance is held constant.

In order to analyze the impact of predators on the gypsy moth-pathogen interaction and the resulting dynamics, we plot gypsy moth phase portraits from the deterministic model with relatively high and low predator carrying capacities. We use the last 30 points of a 50 -iteration of the deterministic model. 
A two-patch model provides a simple spatially explicit extension of the model described above. Populations were simulated in two distinct patches that were spatially coupled through density-independent movement of virus-infected larvae at some rate, $d$ (see for example Fujita and Dwyer 2005). This mechanism of coupling provided a simple way to represent a more complex coupling of several natural enemy populations (e.g., spatial movement of parasitoids see Gould et al. 1990). The important question here is what dynamics may arise when the two spatially coupled patches differ in generalist predator abundance and in particular the possible emergence of coexisting sub-harmonics.

All calculations were performed in R (R Development Core Team 2006). We used the following values for the parameters (taken from Dwyer et al. 2004): $\bar{v}=0.9, \mu=0.32, k=1.06, \rho=$ 0.8, $\lambda=74.6, a=0.98, b=0.05, f=21.33$, and $r=2$. The time-lagged nonparametric crosscorrelation functions were calculated using the Sncf-function in the 'ncf'-package.

\section{RESULTS}

\section{Estimating outbreak periodicity from space-time data with spatial error}

The defoliation data-set encompass $552 \mathrm{~km}^{2}$ of Oak-Pine, 26,796 km² of Oak-Hickory and 11,648 $\mathrm{km}^{2}$ of Maple-Beach-Birch forest type groups that experienced at least one defoliation event between 1975 and 2005. Our analysis of time-series from $2 x 2 \mathrm{~km}^{2}$ raster cells, therefore, encompasses respectively 199, 10036 and 6916 time series of 31 years of length. Figure 1 depicts the spatial-smoothing estimates of the ACF for three forest type groups ranging from the more xeric (Oak-Pine) through the more mesic (Maple-Beech-Birch). The estimated time-lagged crosscorrelation clearly depends on both spatial distance and temporal lag (Fig 1A). Generally the correlations decay both with spatial distance and temporal lag. But the temporal dependence, in particular, is non-monotonic and cyclic because of the regularity of outbreaks. Outbreaks in the Oak-Pine forest type have significant positive autocorrelation at lag 4 and 10 (fig. 1b), outbreaks in 
the Maple-Beech-Birch forest type have significant positive autocorrelation at lags 8 through 10 (fig. 1c), and outbreaks in the Oak-Hickory forest type have significant positive autocorrelation at lags 9 and 10 and marginally significant autocorrelation at lag 4 (fig. 1d). The analysis therefore clearly demonstrates that the superharmonic in the oak-pine and oak-hickory sites is a real phenomenon and not an artifact of averaging across coexisting attractors, though the approximately five-year cycle, where present, is usually a less dominant feature than the more common approximately 10-year cycle.

\section{A natural enemy model}

The model predicts that gypsy moth population increases are followed by an increase in the proportion of virus-infected hosts with a time lag (Fig. 2). This results in overcompensation in disease mortality so that gypsy moth populations crash to very low densities following population peaks. Mortality caused by pathogens remains near $100 \%$ during of the $2-3$ years following the gypsy moth outbreak, and then decline to a low or intermediate level during the troughs. When gypsy moth abundance is low, mortality caused by predators is superimposed on this basic mechanism. Per capita predation rates are greatest when gypsy moth populations are low and this apparently slows the increase in gypsy moth populations back to outbreak levels. Predation rates are furthermore predicted to be more periodic than the predator dynamics because levels of predation depend on both predator abundance and gypsy moth abundance via the type II functional response. Thus, the basic oscillatory pattern resulting from the interaction between gypsy moth and pathogens induces an oscillatory behavior in the predation rate.

Examination of gypsy moth population growth at low population densities shows that predators generally generate a weak Allee effect (Fig. 3a). When we considered high mortality rates (90\%) due to pathogens (which can happen just after the population collapse), the overall growth rate of gypsy moth declined below 1 at relatively high predator abundance (7-20), indicating that a strong Allee effect can result from the interaction between the natural enemies (Fig. 3b). A 
predator population level of 10 or 20 is very high for our theoretical model, though stochasticity sometimes temporarily causes such levels when the predator carrying capacity exceeds 7. When predator populations fluctuate at low densities, gypsy moth growth rate was not affected substantially (Fig. 3). In this case, gypsy moth populations increase more rapidly following population crashes and the period of the outbreak cycle is significantly shortened ( $~ 6$ years for the parameter values used here) and dominated by the virus-moth interaction (Fig.4).

Spectral analysis of simulated time series predicts that the dominant period of gypsy moth populations should increase with increasing predator carrying capacity. Plots of the standardized power of the periods show that the dominant period increases smoothly from 6 to more than 10 years with increasing predator carrying capacity, though the strength of periodicity progressively decrease (Fig. 4ab). There is some evidence of a subdominant superharmonic that increase from 3 years up to around 5 years with increasing predator carrying capacity (Fig. 4ab). The pattern is more pronounced in the deterministic simulations (Fig. 4b). At high predator densities (carrying capacity $>9$ ) the predator can drive the gypsy moth extinct. Phase portraits show how the predators amplify oscillations: when predator carrying capacity is low, gypsy moth populations orbit in a relatively compact part of the phase plane (Fig. 5b) but at high predator carrying capacities, populations orbit in a much broader (low-frequency) orbit (Fig. 5a).

One facet of the model's behavior crudely matches the empirical findings: the cycle-length is predicted to increase from around 6 years to around 10-12 years as a function of generalist predator pressure (Smith 1985, Liebhold et al. 2005, Johnson et al. 2006a). However the non-spatial model also exhibits a behavior that is contrary to available empirical evidence. The non-spatial model predicts the period of gypsy moth outbreaks to increase continuously as a function of predation pressure. This is at odds with our empirical analysis, which revealed the coexistence of a low- and a high-harmonic cycle across the landscape but no intermediate frequencies (Fig. 1, see also Johnson et al. 2006a). In a preliminary attempt to explain this discrepancy, we studied the model's behavior in a spatially-coupled two-patch version of the model with heterogeneity in 
predator carrying capacity. In the first set of analyses we studied the periodic behavior of the system assuming a range of values for the dispersal rate $(d)$ when we assumed that one patch (patch 1 ) had a high predator carrying capacity $\left(\mathrm{K}_{1}=6\right)$ and the other patch (patch 2) had a low predator carrying capacity $\left(K_{2}=1\right)$. In the absence of spatial coupling, these two patches would cycle independently with a 8 and 6 year periodicity, respectively, as illustrated by the power spectra depicted in figure 6a and 6c. The upper middle panel (Fig. 6b) shows how the power spectrum of the 'slower' patch $\left(\mathrm{K}_{1}=6\right)$ evolves as dispersal increase between the patches. With increasing dispersal (at $d$ around 0.05) the slower cycle $\left(K_{1}=6\right)$ gets first entrained on the faster cycle (the dominant period is 6 years like that of patch 2, rather than the inherent 8-year cycle in the absence of coupling), then as coupling increases further (at $d$ around 0.10) a 12-year subharmonic period appears (Fig. 6b). The periodicity of the low predation patch (patch 2) remains qualitatively unaffected. We show examples of the predicted time series in the electronic supplement (Fig. A3).

In the second set of analysis we study how the difference in predator carrying capacity affect the periodic behavior of the coupled system. We assume dispersal rate to be high $(\mathrm{d}=0.12)$ and the predator carrying capacity in patch 2 to be low and constant at $K_{2}=1$. We then vary the predator carrying capacity in patch 1 between 1 (i.e. no heterogeneity) and 6 (strong heterogeneity). With no heterogeneity the power spectra of the patches are identical with a dominant 6-year cycle (fig. 6d). As the heterogeneity increases $\left(2<\mathrm{K}_{1}<5\right)$ we can see that the entrainment of the slower cycle on the faster cycle is robust (fig. 6e). In the absence of coupling the period would be predicted to shift gradually from 6 years to 8 years under this scenario (Fig. 4). The appearance of the subharmonic depends strongly on the degree of patch differences. Only when the predator carrying capacities are widely different $\left(\mathrm{K}_{1}>5\right)$ does the subharmonic appear (Fig. 6f). While a comprehensive analysis of the two-patch model is outside the scope of this paper, these preliminary analyses serves as a proof-of-concept that in the presence of spatial coupling, superharmonic attractors can coexist whereas nonharmonic attractors cannot, thus offering a landscape-level mechanism of discrete jumps in periodicity while the non-spatial theoretical model predicts a smooth transition. 


\section{DISCUSSION}

Periodic oscillations in forest insect populations have long attracted considerable attention and a variety of mechanisms have been proposed to explain them (Myers 1988, Berryman 1996, Kendall et al. 1999, Liebhold and Kamata 2000). These mechanisms include host-pathogen interactions, host-parasitoid interactions, maternal effects, and induced host defenses. Though each of these mechanisms appears to be capable of generating population cycles, the definitive causes of periodic oscillations have remained elusive in most species. Furthermore, there is growing evidence that population cycles are not necessarily caused by interactions with a single species or a single guild of species; instead, it appears that many such cycles are the result of complex trophic interactions (Royama 1997, Turchin et al. 2003). Geographic variation in the strength of the trophic interactions can in turn result in geographic variation in population dynamics (e.g. Bjørnstad et al. 1998). Periodic oscillations in abundance have been widely observed in the dynamics of many different types of animal populations including foliage-feeding insects such as the gypsy moth. Our analyses of time-space correlations (Fig.1a,b) confirm that in addition to the existence of simple periodic oscillations of period 9-10 years, some populations also exhibit superharmonic oscillations with periods of 4-5 years, as previously discussed in Johnson et al. (2006a). Furthermore, the strength of the superharmonic varies among different forest types.

There are few precedents in the literature on our observations of superharmonic oscillations in animal populations. In a manner somewhat reminiscent of the behavior of gypsy moth populations, Volney and McCullough (1994) found that populations of the jack pine budworm, Choristoneura pinus, located in dry sites exhibit oscillations with a period of 5-6 years but populations in mesic sites are characterized by outbreak periods of ca. 10 years however there were no populations that exhibited both periods. There are many examples of "period doubling" bifurcations that have been recognized in various nonlinear population models (e.g. Kot 1989, Stone 1993) but the superharmonic oscillations (Fig. 1a, b) seen in the gypsy moth appear to be the best 
empirical evidence for this phenomenon to date. Moreover, none of the models previously found to exhibit period doubling would seem to apply directly to the gypsy moth and therefore they do not adequately explain the mechanisms responsible for superharmonic oscillatory behavior.

Host-pathogen interactions have been implicated as causes of population cycles in many forest insect species, such as the larch budmoth (Anderson and May 1980), western tent caterpillar (Myers 2000), the Douglas-fir tussock moth (Shepherd et al. 1988) as well as in the gypsy moth (Elkinton and Liebhold 1990, Dwyer and Elkinton 1993, Dwyer et al. 2004). However, despite the fact that pathogens, such as baculoviruses, sometimes exhibit massive epizootics when hosts reach high densities, these interactions alone often do not satisfactorily explain oscillatory patterns seen in hosts (Turchin et al. 2003). Unfortunately, there have been relatively few investigations of how insect pathogens interact with other mortality agents (Hochberg 1989). Generalist predators have long been recognized to play critical roles in the dynamics of forest insect populations though there is scant evidence that they, alone, are capable of generating population cycles. We report here on a model that describes both the interaction between the gypsy moth and it's viral pathogen as well as the interaction between this insect and generalist predator populations. This model exhibits periodic oscillations in gypsy moth populations as a result of the overcompensatory numerical response of the virus. At high host levels, the virus causes extensive mortality that causes outbreak populations to crash to very low levels. Following this crash, populations slowly increase to outbreak levels again (Fig. 2). Simulations indicated that there is a direct link between declines in predation rate and increases in gypsy moth populations (Fig. 2). Predation serves to slow the return of gypsy moth populations to outbreak levels. As a result, gypsy moth oscillation period is positively related to predator carrying capacity (Fig. 4). In the absence of predators, populations are predicted to exhibit weak oscillations with periods of 5-6 years (Fig. 4). However, as the predator carrying capacity increases (and gypsy moth growth rates correspondingly decrease), the dominant period of oscillations progressively increases. 
Our results suggest an explanation for the geographical variation in gypsy moth populations that are observed in the field (Fig. 1). Populations of the gypsy moth's small mammal predators are known to be more abundant at mesic than at xeric sites (Smith 1985, Yahner and Smith 1991, Liebhold et al. 2005). Gypsy moth outbreaks are furthermore known to be more frequent at dry oak-dominated sites (Bess et al. 1947, Houston and Valentine 1977). Our model indicates that the higher abundance of generalist predators in the mesic sites serves to prolong the build-up of gypsy moths following the outbreak crash, thereby explaining the lower outbreak frequency at these sites. Previous theory predicts that the type II functional response of generalist predators to gypsy moth densities might create an Allee effect (Gascoigne and Lipcius 2004) and indeed our model confirms this (Fig. 3). Interestingly, as predator populations increase, the Allee effect shifts from being weak to strong (Fig. 3b). Predation together with with mate-finding failure may be at the heart of the significant Allee effect evidenced in the Gypsy moth invasion of the US (Johnson et al. 2006b, Tobin et al. 2007).

While simulations presented here demonstrate that variability in generalist predator densities can explain the observed geographical variation in the periodicity of gypsy moth populations, we cannot completely exclude other trophic interactions that may contribute to this variation. For example, it is possible that geographical variation in climate or host tree species composition affects the dynamics of the gypsy moth / pathogen interactions. Another possibility is that geographical variation in the abundance of parasitoids (caused by variation in the abundance of alternate hosts) is responsible for the observed variability in gypsy moth dynamics. Despite the existence of a multitude of possible alternate explanations for the observed geographical variation in dynamics, we feel that the hypothesis explored here is the most likely given the considerable empirical evidence for both the central role played by small mammals in gypsy moth dynamics and evidence of geographical variation in generalist predator abundance and impact on gypsy moth survival (Smith 1985, Yahner and Smith 1991, Elkinton et al. 1996, Jones et al. 1998, Liebhold et al. 2005). 
The finding that gypsy moth dynamics vary among different areas in relation to the carrying capacity of generalist predators suggest a pattern somewhat similar to that proposed for the transition in dynamics of certain cyclic Fennoscandian herbivores. Populations of the autumnal moth, E. autumnata, and voles of the genera Microtus and Clethrionomys exhibit stronger, and more high frequency outbreaks in Northern latitudes but to the south, populations exhibit lower frequency oscillations or non-periodic behavior. Klemola et al. (2002) attempted to explain this gradient by the increased dominance of generalist predators at lower latitudes. Generalist predators do not generate delayed density-dependence because there is no numerical feedback and therefore an abundance of generalist predators (a low density of specialist predators) tends to stabilize prey population. In our case, cycles are mainly produced by an interaction with a specialist pathogen (instead of a specialist predator like in Klemola et al. 2002) but the overall effect of generalist predators moderating the fluctuations of prey populations seems to be similar.

One noteworthy aspect of our non-spatial model is that outbreak period is predicted to increase as a continuous function of predator carrying capacity (Fig. 4). This gradual shift in oscillation period is somewhat similar to that observed along latitudinal gradients of Fennoscandian herbivores described above. However, in the case of naturally-occurring gypsy moth populations, oscillations are dominated either by a 4-5 year period or a 9-10 year period or both but intermediate periods are not observed (Fig. 1). The ultimate explanation for the lack of continuity in oscillation periods among different habitats is worthy of further study. However our 2-patch model provides a 'proof of concept' for spatial coupling among heterogeneous patches as a possible explanation. In the model spatial coupling between forest types only permits the coexistence of cycles with the same period or subharmonics thereof (Fig. 6); populations in forests with low-predator carrying capacities (e.g., oak-pine) therefore tend to outbreak with twice the frequency of that found in forests with high predator carrying capacities (e.g., maple-beach-birch). In the latter case, we may observe double peaked spectra with a dominant cycle and a subdominant sub-/super-harmonic as was observed in the oak-hickory type groups (Fig. 1c). 


\section{ACKNOWLEDGMENTS}

We thank Derek Johnson for his insightful comments and suggestions. This work was supported by the National Research Initiative of the USDA Cooperative State Research, Education and Extension Service Grants to O.N.B. and A.M.L. (2002, 2006)

\section{REFERENCES}

Anderson, R. M. and R. M. May. 1980. Infectious diseases and population cycles of forest insects. Science 210:658-661.

Baltensweiler, W., G. Benz, P. Bovey, and V. Delucchi. 1977. Dynamics of Larch Bud Moth Populations. Annual Review of Entomology 22:79-100.

Berryman, A. A. 1996. What causes population cycles of forest Lepidoptera? Trends in Ecology and Evolution 11:28-32.

Berryman , A. A. 2002. Population cycles: Causes and analyses. Pages 3-28 in A. A. Berryman editor. Population Cycles: The Case of Trophic Interactions. Oxford University Press, Oxford.

Bess, H. A., S. H. Spurr, and E. W. Littlefield. 1947. Forest site conditions and the gypsy moth. Harvard Forest Bulletin 22:1-56.

Bjørnstad, O. N. and W. Falck. 2001. Nonparametric spatial covariance functions: estimation and testing. Environmental and Ecological Statistics 8:53-70.

Bjørnstad, O. N., W. Falck, and N. C. Stenseth. 1995. A geographic gradient in small rodent density fluctuations: a statistical modelling approach. Proceedings of Royal Society London, B. 262:127-133.

Bjørnstad, O. N., M. Peltonen, A. M. Liebhold, and W. Baltensweiler. 2002. Waves of larch budmoth outbreaks in the European Alps. Science 298:1020-1023. 
Bjørnstad, O. N., N. C. Stenseth, T. Saitoh, and O. C. Lingjære. 1998. Mapping the regional transitions to cyclicity in Clethrionomys rufocanus: spectral densities and functional data analysis. Researches on Population Ecology 40:77-84.

Campbell, R. W. 1975. The gypsy moth and its natural enemies. U.S. Department of Agriculture, Washington DC.

Campbell, R. W. and R. J. Sloan. 1977. Natural Regulation of Innocuous Gypsy Moth (Lepidoptera-Lymantriidae) Populations. Environmental Entomology 6:315-322.

Ciesla, W. M. 2000. Remote sensing in forest health protection. U.S. Department of Agriculture, Washington DC.

Courchamp, F., T. Clutton-Brock, and B. Grenfell. 1999. Inverse density dependence and the Allee effect. Trends in Ecology \& Evolution 14:405-410.

Doane, C. C. 1970. Primary pathogens and their role in the development of an epizootic in the gypsy moth. Journal of Invertebrate Pathology 15:21-33.

Dwyer, G., J. Dushoff, J. S. Elkinton, and S. A. Levin. 2000. Pathogen-driven outbreaks in forest defoliators revisited: Building models from experimental data. American Naturalist 156:105-120.

Dwyer, G., J. Dushoff, and S. H. Yee. 2004. The combined effects of pathogens and predators on insect outbreaks. Nature 430:341-345.

Dwyer, G. and J. S. Elkinton. 1993. Using simple models to predict virus epizootics in gypsy moth populations. Journal of Animal Ecology 62:1-11.

Elkinton, J. S., W. M. Healy, J. P. Buonaccorsi, G. H. Boettner, A. M. Hazzard, H. R. Smith, and A. M. Liebhold. 1996. Interactions among gypsy moths, white-footed mice, and acorns. Ecology 77:2332-2342.

Elkinton, J. S. and A. M. Liebhold. 1990. Population dynamics of gypsy moth in North America. Annual Review of Entomology 35:571-596. 
Elkinton, J. S., A. M. Liebhold, and R. M. Muzika. 2004. Effects of alternative prey on predation by small mammals on gypsy moth pupae. Population Ecology 46:171-178.

Epperson, B. K. 1995. Fine-scale spatial structure: correlations for individual genotypes differ from those for local gene frequencies. Evolution 49:1022-1026.

Esper, J., U. Buntgen, D. C. Frank, D. Nievergelt, and A. Liebhold. 2007. 1200 years of regular outbreaks in alpine insects. Proceedings of the Royal Society B-Biological Sciences 274:671-679.

Ferrari, M. J., R. F. Grais, N. Bharti, A. J. K. Conlan, O. N. Bjornstad, L. J. Wolfson, P. J. Guerin, A. Djibo, and B. T. Grenfell. 2008. The dynamics of measles in sub-Saharan Africa. Nature 451:679-684.

Fujita, P. and G. Dwyer. 2005. Genetic variation in field populations of the gypsy moth pathogen nucleopolyhedrosis virus. Ecological Society of America Annual Meeting, Montreal.

Gascoigne, J. C. and R. N. Lipcius. 2004. Allee effects driven by predation. Journal of Applied Ecology 41:801-810.

Goodwin, B. J., C. G. Jones, E. M. Schauber, and R. S. Ostfeld. 2005. Limited dispersal and heterogeneous predation risk synergistically enhance persistence of rare prey. Ecology 86:3139-3148.

Gould, J. R., J. S. Elkinton, and W. E. Wallner. 1990. Density-Dependent Suppression of Experimentally Created Gypsy-Moth, Lymantria-Dispar (Lepidoptera, Lymantriidae), Populations by Natural Enemies. Journal of Animal Ecology 59:213-233.

Grenfell, B. T., O. N. Bjørnstad, and J. Kappey. 2001. Travelling waves and spatial hierarchies in measles epidemics. Nature 414:716-723.

Hansson, L. and H. Henttonen. 1985. Gradients in density variations of small rodents: the importance of latitude and snow cover. Oecologia 67:394-402.

Hochberg, M. E. 1989. The Potential Role of Pathogens in Biological-Control. Nature 337:262-265. 
Houston, D. R. and H. T. Valentine. 1977. Comparing and Predicting Forest Stand Susceptibility to Gypsy Moth. Canadian Journal of Forest Research-Revue Canadienne De Recherche Forestiere 7:447-461.

Johnson, D. M., A. M. Liebhold, and O. N. Bjornstad. 2006a. Geographical variation in the periodicity of gypsy moth outbreaks. Ecography 29:367-374.

Johnson, D. M., A. M. Liebhold, O. N. Bjornstad, and M. L. McManus. 2005. Circumpolar variation in periodicity and synchrony among gypsy moth populations. Journal of Animal Ecology 74:882-892.

Johnson, D. M., A. M. Liebhold, P. C. Tobin, and O. N. Bjornstad. 2006b. Allee effects and pulsed invasion by the gypsy moth. Nature 444:361-363.

Jones, C. G., R. S. Ostfeld, M. P. Richard, E. M. Schauber, and J. O. Wolff. 1998. Chain reactions linking acorns to gypsy moth outbreaks and Lyme disease risk. Science 279:1023-1026.

Kendall, B. E., C. J. Briggs, W. W. Murdoch, P. Turchin, S. P. Ellner, E. McCauley, R. M. Nisbet, and S. N. Wood. 1999. Inferring the causes of population cycles: a synthesis of statistical and mechanistic modeling approaches. Ecology 80:1789-1805.

Kendall, B. E., J. Prendergast, and O. N. Bjørnstad. 1998. The macroecology of population dynamics: taxonomic and biogeographic patterns in population cycles. Ecology Letters 1:160-164.

Klemola, T., M. Tanhuanpaa, E. Korpimaki, and K. Ruohomaki. 2002. Specialist and generalist natural enemies as an explanation for geographical gradients in population cycles of northern herbivores. Oikos 99:83-94.

Kot, M. 1989. Diffusion-Driven Period-Doubling Bifurcations. Biosystems 22:279-287.

Liebhold, A., J. Elkinton, D. Williams, and R. M. Muzika. 2000. What causes outbreaks of the gypsy moth in North America? Population Ecology 42:257-266.

Liebhold, A. and N. Kamata. 2000. Introduction - Are population cycles and spatial synchrony a universal characteristic of forest insect populations? Population Ecology 42:205-209. 
Liebhold, A. M., K. W. Gottschalk, E. R. Luzader, D. A. Mason, and R. R. Bush. 1997. Gypsy moth in the United States: An Atlas. USDA Forest Service, Washington DC.

Liebhold, A. M., K. F. Raffa, and A. L. Diss. 2005. Forest type affects predation on gypsy moth pupae. Agricultural And Forest Entomology 7:179-185.

Murdoch, W. W., C. J. Briggs, and R. M. Nisbet. 2003. Consumer-resource dynamics. Princeton University Press, Princeton.

Myers, J. H. 1988. Can a general hypothesis explain population cycles of forest lepidoptera. Advances in Ecological Research 18:179-242.

Myers, J. H. 2000. Population fluctuations of the western tent caterpillar in southwestern British Columbia. Population Ecology 42:231-241.

Priestley, M. B. 1981. Spectral analysis and time series. Academic Press, London.

R Development Core Team. 2006. R: A language and environment for statistical computing. R Foundation for Statistical Computing, Vienna.

Royama, T. 1997. Population dynamics of forest insects: are they governed by single or multiple factors? Pages 37-48 in A. D. Watt, N. E. Stork, and M. D. Hunter, editors. Forests and Insects. Chapman and Hall, London.

Ruohomaki, K., T. Virtanen, P. Kaitaniemi, and T. Tammaru. 1997. Old mountain birches at high altitudes are prone to outbreaks of Epirrita autumnata (Lepidoptera: Geometridae). Environmental Entomology 26:1096-1104.

Schauber, E. M., R. S. Ostfeld, and C. G. Jones. 2004. Type 3 functional response of mice to gypsy moth pupae: is it stabilizing? Oikos 107:592-602.

Seabloom, E. W., O. N. Bjornstad, B. M. Bolker, and O. J. Reichman. 2005. Spatial signature of environmental heterogeneity, dispersal, and competition in successional grasslands. Ecological Monographs 75:199-214.

Shepherd, R., D. D. Bennet, J. W. Dale, S. Tunnock, R. E. Dolph, and R. W. Thier. 1988. Evidence of synchronized cycles in outbreak patterns of Douglas-fir tussock moth, Orgyia 
pseudotsugata (McDunnough)(Lepidoptera: Lymantriidae). . Memoirs of the Entomological Society of Canada, Ottawa 146:107-121.

Smith, H. R. 1985. Wildlife and the Gypsy Moth. Wildlife Society Bulletin 13:166-174.

Stone, L. 1993. Period-Doubling Reversals and Chaos in Simple Ecological Models. Nature 365:617-620.

Tobin, P. C., S. L. Whitmire, D. M. Johnson, O. N. Bjornstad, and A. M. Liebhold. 2007. Invasion speed is affected by geographical variation in the strength of Allee effects. Ecology Letters 10:36-43.

Turchin, P. and I. Hanski. 1997. An empirically based model for latitudinal gradient in vole population dynamics. American Naturalist 149:842-874.

Turchin, P., S. N. Wood, S. P. Ellner, B. E. Kendall, W. W. Murdoch, A. Fischlin, J. Casas, E. McCauley, and C. J. Briggs. 2003. Dynamical effects of plant quality and parasitism on population cycles of larch budmoth. Ecology 84:1207-1214.

Varley, G. C., G. R. Gradwell, and M. P. Hassell. 1973. Insect population ecology: an analytical approach. Blackwell Scientific, Oxford.

Volney, W. J. A. and D. G. McCullough. 1994. Jack Pine Budworm Population Behavior in Northwestern Wisconsin. Canadian Journal of Forest Research-Revue Canadienne De Recherche Forestiere 24:502-510.

Wang, M. H. and M. Kot. 2001. Speeds of invasion in a model with strong or weak Allee effects. Mathematical Biosciences 171:83-97.

Yahner, R. H. and H. R. Smith. 1991. Small Mammal Abundance and Habitat Relationships on Deciduous Forested Sites with Different Susceptibility to Gypsy-Moth Defoliation. Environmental Management 15:113-120. 


\section{FIGURES}

Figure 1. Correlation functions derived by application of space-time correlation with spatial error to historical (1975-2002) binary gypsy moth defoliation data. (a) examples of the time-lagged spatial cross-correlation functions. The three black dots in panel (a) and (b) illustrate (for time lags 1, 2, and 9) how the 'spatially-smoothed' temporal autocorrelation functions are constructed from the time lagged spatial cross-correlation functions. (b)-(c) 'spatially-smoothed' temporal autocorrelation functions in forests ranging from wet (maple-beech-birch) to dry (oak-pine). The correlograms show that the former cycle with a 9-10 year period but the latter with a 4-5 year period (see also Johnson et al. 2006a). Intermediate forest types (oak-hickory) have a dominant 9-10 year cycle and a subdominant super-harmonic.

Figure 2. Fluctuation of gypsy moth abundance and mortality rates due to predators and pathogens $(K=5, \tilde{\sigma}=0.3)$.

Figure 3. Effects of predator abundance on low density populations of gypsy moth, when (a) no host is infected with virus; (b) $90 \%$ of larvae are infected with virus. Solid black line refers to $K=$ 20, solid grey line refers to $K=10$, dashed black line refers to $K=7$, dashed grey line refers to $K=$ 2. The horizontal grey line indicates a growth rate equal to 1 (the Allee threshold).

Figure 4. Effects of predator carrying capacity on the standardized power spectra of the gypsy moth modl. (a) stochastic model and average of 500 simulations ( $\tilde{\sigma}=0.3$ ); (b) deterministic model assuming the predator density constant. We iterated the model for 200 generations and quantified the periodicity based on the last 100 generations. 
Figure 5: Phase portraits representing pathogen density vs host density $\left(\log _{10}\right)$, with predators set to a constant ( $\tilde{\sigma}=0$ ), (a) $K=7$, (b) $K=2$. We iterated the model for 50 generations for each couple of initial values and we plotted only the last 30 points. We used the same initial values as Dwyer et al. (2004) for their figure 3b.

Figure 6. Predicted dynamics of the two-patch model with varying dispersal (upper panel) and heterogeneity in predator carrying capacity (lower panel). In the top panel predator carrying capacities are assumed constant at $K=6$ (patch 1 ) and $K=6$ (patch 1 ) and movement rates assumed to vary. (a) and (c) shows the predicted power spectra for the two patches in the absence of coupling. (b) shows the predicted power spectra for patch 1 (the high predation patch) as dispersal rates increase. In the bottom panel predator carrying capacity in patch 2 is assumed constant at $\mathrm{K}=$ 1 and dispersal constant at 0.12 while the carrying capacity in patch 1 is varied. (d) and (f) shows the predicted power spectra for $K=6$ and $K=1$. (e) shows the predicted power spectra for patch 1 as the predator carrying capacity is varied. 

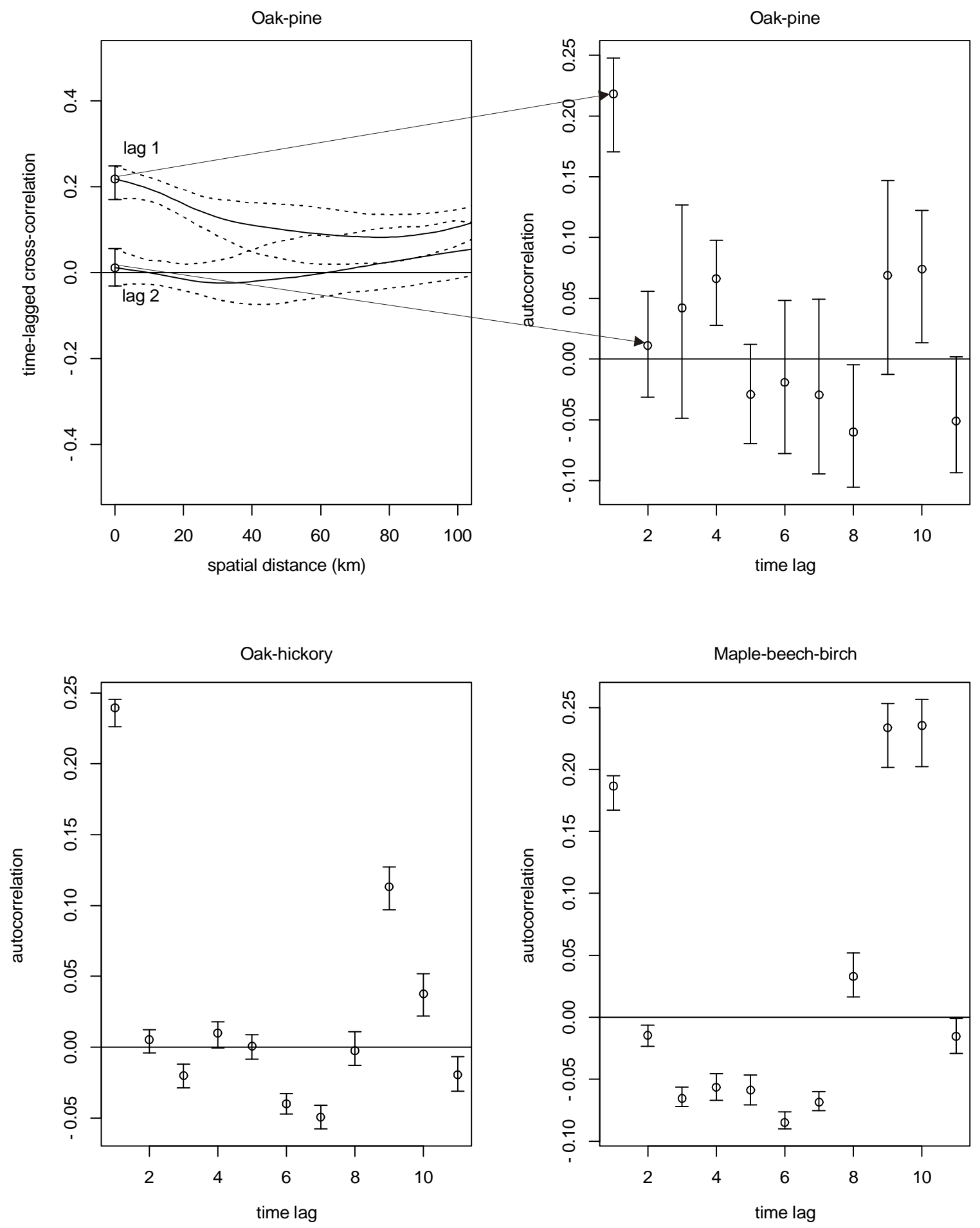

Figure 1. 


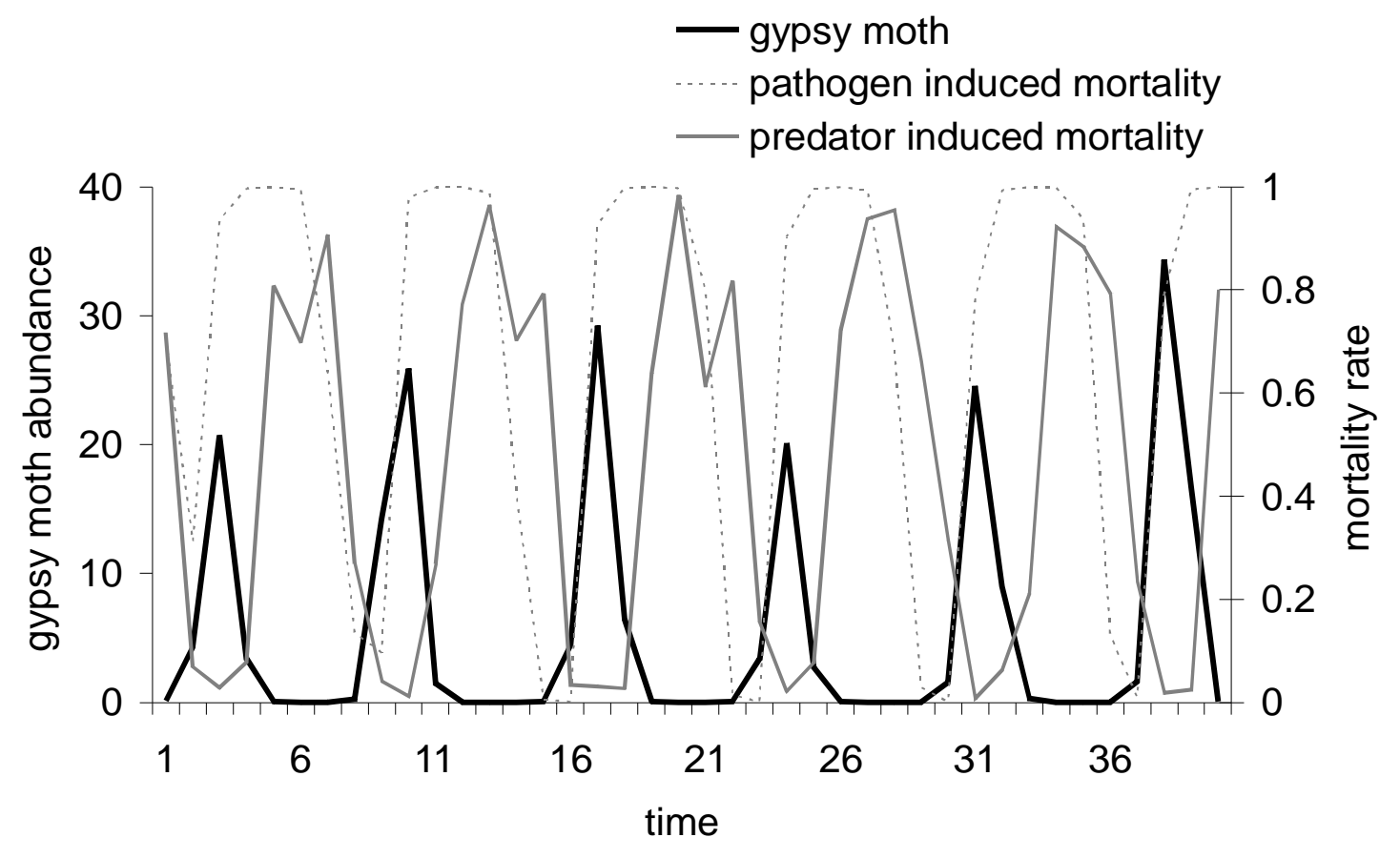

Figure 2. 
B. $0 \%$ viral prevalence

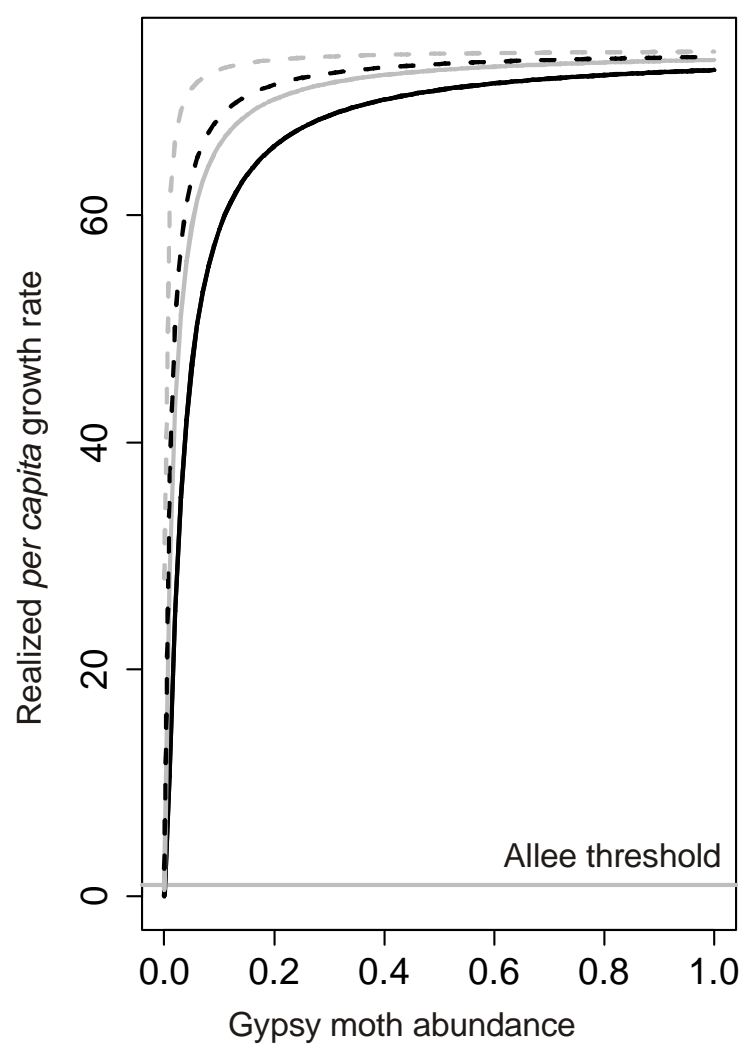

B. $90 \%$ viral prevalence

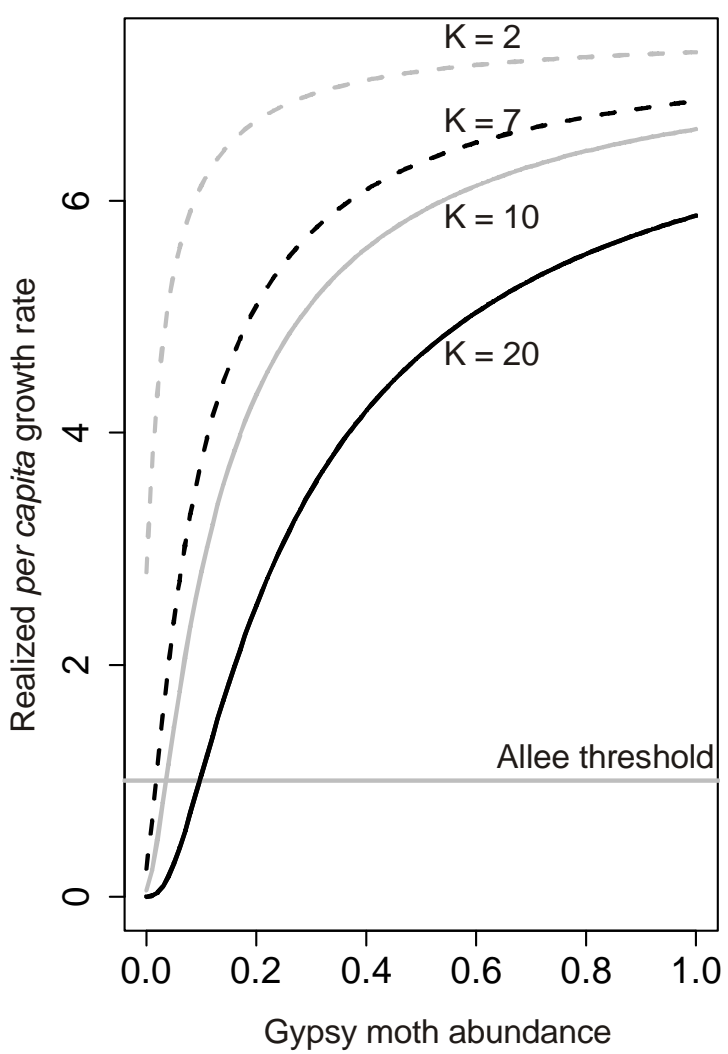

Figure 3. 

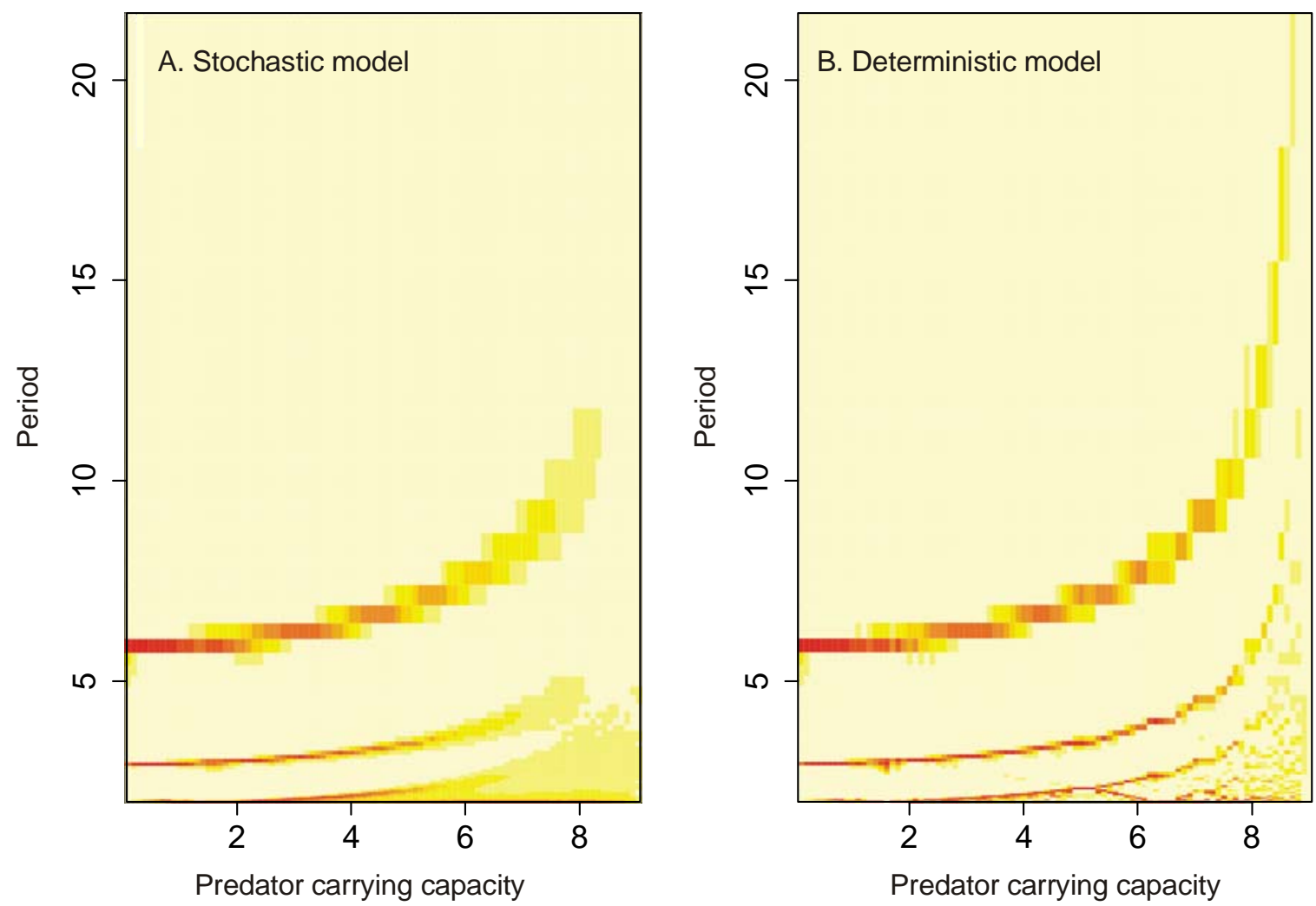

Figure4. 

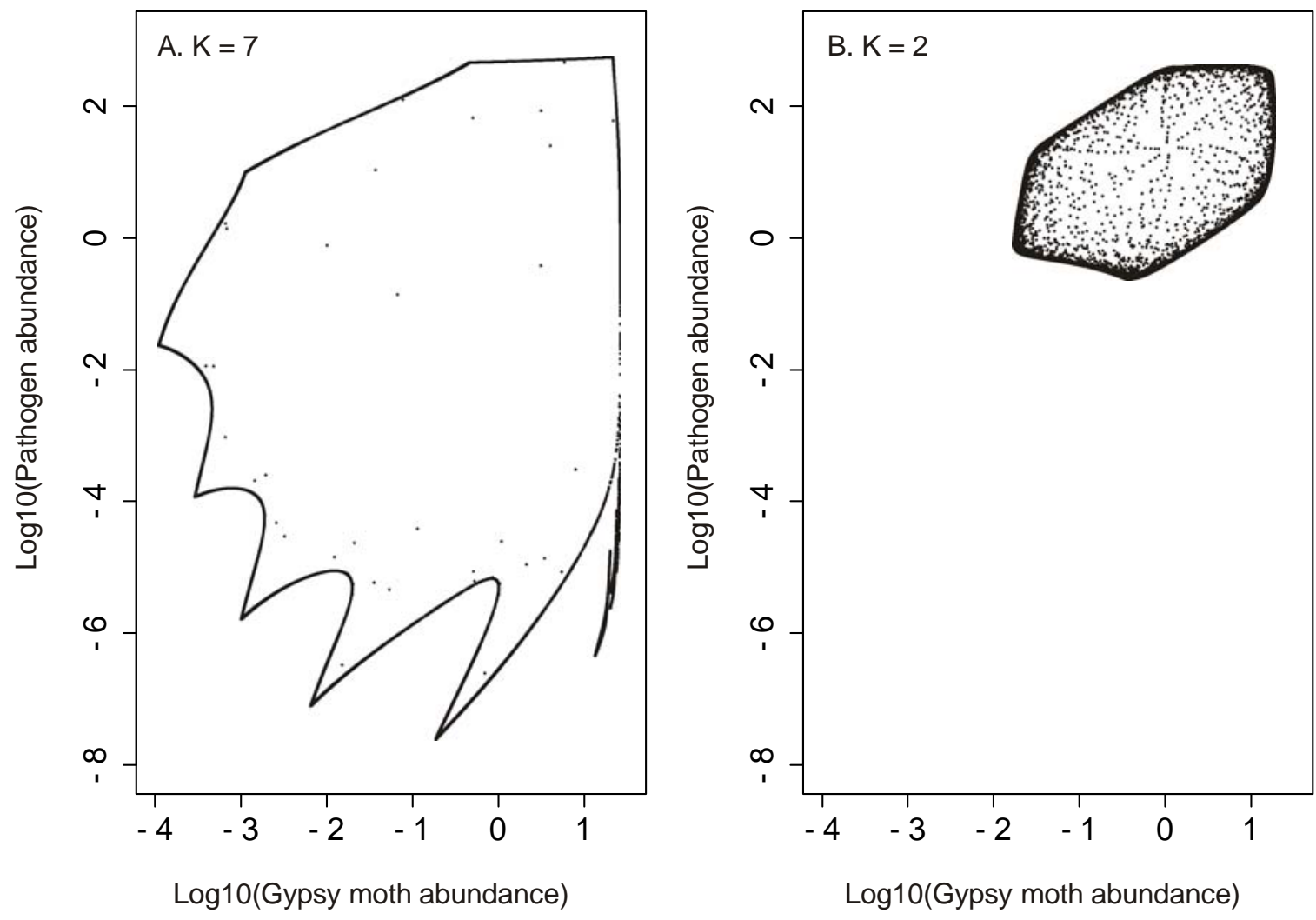

Figure 5. 

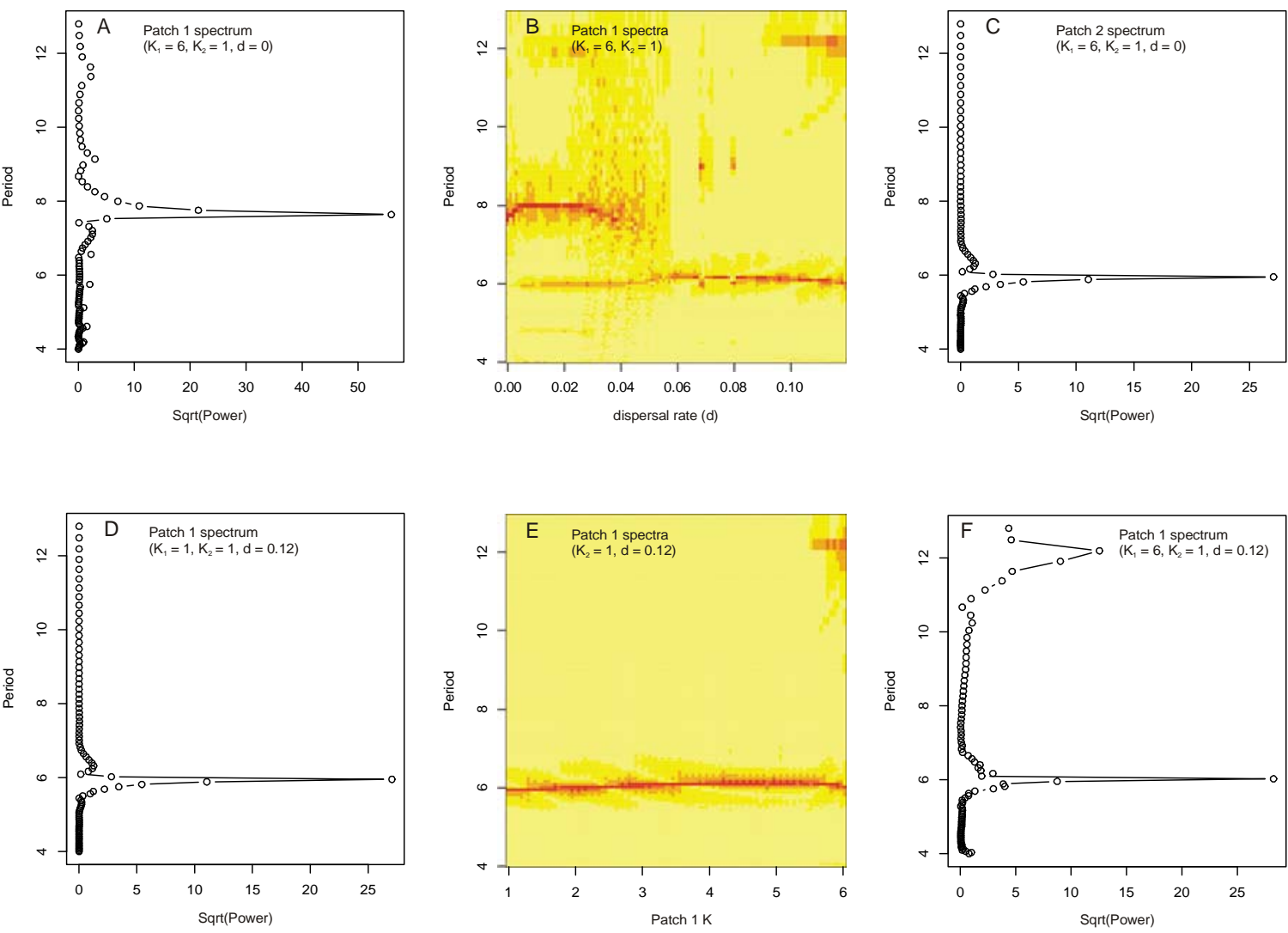

Figure 6. 